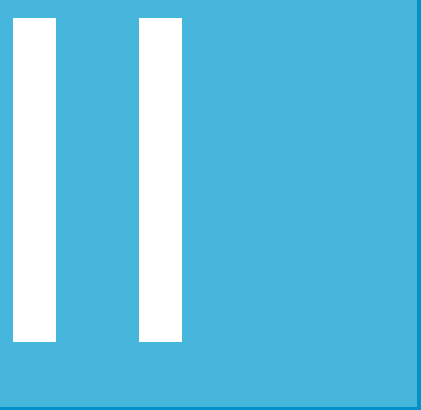

\title{
LA CONSTRUCCIÓN DEL LÍDER
}

\section{The construction of the leader}

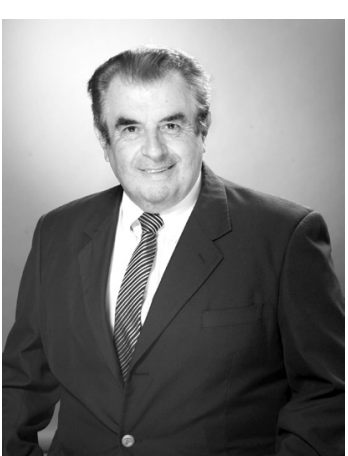

\section{Mario Pereyra Lavandina}

Licenciado en Psicología por la Universidad Nacional de Córdoba. Licenciado en Teología por la Universidad Adventista del Plata. Doctor en Psicología por la Universidad Católica de Córdoba. Actualmente se desempeña como docente de la Universidad de Montemorelos. Asimismo realizó actividades de docencia en diversos posgrados organizados por dicha universidad. Ha publicado numerosos artículos en revistas nacionales y extranjeras. Del mismo modo desarrolla ponencias a nivel nacional e internacional. 


\section{Resumen}

En estos nuevos tiempos hipermodernos la figura del líder se caracteriza por trasmitir una imagen exitosa en medio de los aplausos y aclamaciones de la multitud. Muy diferente son los líderes que despliega la historia sagrada de la Biblia. Allí el hombre sobresaliente aparece con sus debilidades y fracasos, con virtudes que le ayudan a sobreponerse a la adversidad, encarnando valores excelsos que lo constituyen en modelos siempre vigentes. En el presente artículo se analiza diferentes perspectivas de líderes bíblicos en relación a la figura singular de Judá, el cuarto hijo del patriarca Jacob, fundador del pueblo de Israel.

Palabras clave: Líder, liderazgo, carácter, ética.

\section{Abstract}

In these new hypermodern times the figure of the leader is characterized by convey a successful image amid the applause and the crowd cheers. However, very different are the leaders that display the sacred history of the bible. Within their context a remarkable character appears with his weakness and failures and only God's grace helps overcome the adversity and incarnating lofty values that constitute existing models always. In this paper we analyze different perspectives on biblical leaders regarding the singular figure of Judah, the fourth son of the patriarch Jacob founder of Israel.

Keywords: Leader, leadership, ethics. 
¡Tú, Judá, hijo mío!

Eres como un cachorro de león cuando deja de devorar a su víctima: se agacha, se echa en el suelo, como si fuera un león grande. ¿Y quién se atreverá a molestarlo? Nadie le quitará el poder a Judá ni el cetro que tiene en las manos, hasta que venga el dueño del cetro, a quien los pueblos obedecerán". Jacob (Gn 49:9-10; DHH).

\section{Las cualidades de un líder}

En estos "nuevos tiempos hipermodernos" (Lipovetsky et al., 2006) la figura del líder se caracteriza por trasmitir una imagen exitosa, en medio de los aplausos y aclamaciones de la multitud, exhibiendo una sonrisa que jamás se apaga frente a las luces, flashes y cámaras, encabezando el rating de la popularidad, haciendo brillar su imagen en la TV, los diarios y las revistas de los kioscos. El líder actual es un profesional de los medios de comunicación, en los cuales importa más el aparecer que el ser, el gesto triunfal que la inteligencia, las habilidades dialécticas que una moral incorruptible. Es que en esta cultura o "civilización del espectáculo", como dice Vargas Llosa (2012), "vivimos la primacía de las imágenes sobre las ideas" (Ídem, 46), cuando se privilegia "la banalidad sobre lo profundo y lo frívolo sobre lo serio" (Ídem, 47), donde se entiende "el mundo, la vida, según la cual todo es apariencia, es decir teatro, juego y diversión" (Ídem, 51). Son tiempos "light" (Rojas, 1999), sin valores consistentes y sustentadores de conductas íntegras, nobles y elevadas, por lo tanto, en este contexto los líderes políticos, de los negocios, del deporte, entre otros, representan actitudes edulcoradas, de verbosidad gratuita, narcisista, resultando maestros de la pose y del gesto triunfal. Son líderes semejantes a los castillos frágiles construidos sobre la arena que se deshacen al primer golpe del viento.

Muy diferente son los líderes que despliega la historia sagrada de la Biblia. Allí el hombre sobresaliente aparece con sus debilidades y fracasos, con virtudes que le ayudan a sobreponerse a la adversidad, encarnando valores excelsos que lo constituyen en modelos siempre vigentes. Así, por ejemplo, Abraham personifica el valor de la fe (Ro 4:11), capaz de sacrificar a su único 
hijo debido a su confianza en Dios (Heb 11:17-18). También Moisés fue un gran líder que condujo el pueblo de Israel durante 40 años, actuando como intercesor (Éx 32:11-14), concediéndoles leyes y una organización que duró por siglos. Lo mismo podríamos decir de otros grandes líderes de la historia bíblica como José, Josué, Gedeón, Samuel, David, Daniel, hombres que se destacaron por su fidelidad, abnegación, valentía, sabiduría, integridad, que la Biblia llega a reconocerlos diciendo de ellos que "el mundo no era digno" (Heb 11:38) de los tales. En consecuencia, el estudio del liderazgo debe transitar necesariamente por la consideración de alguno de esos hombres distinguidos, poseedores de cualidades relevantes, que pueden erigirse como modelos a imitar. Quizá uno de los ejemplos más admirable y menos conocido lo constituya la figura singular de Judá, el cuarto hijo del patriarca Jacob, fundador del pueblo de Israel, quien dio nombre al pueblo judío, siendo un protagonista exclusivo de la historia antigua, dejando un legado que continúa en el presente y se proyecta hasta el futuro eterno.

\section{Una historia difícil}

La madre de Judá fue Lea, una mujer desdichada debido a que fue desechada por su esposo y desplazada por su hermana, con quien tuvo que compartir su marido en un matrimonio poligámico. Lea pugnando por ser reconocida dio a luz su cuarto hijo varón, a quien le puso un nombre singular y muy significativo: Judá, que significa "alabanza" (Gn 29:35). En los tiempos bíblicos el nombre propio reproducía el carácter del individuo, era una declaración del destino que le esperaba, una calificación de la naturaleza del ser, algo muy diferente de lo que actualmente entendemos por el nombre que es la mera designación de la persona. ¿Qué esperaba Lea al darle ese nombre a su hijo? ¿Por qué "alabanza"? Seguramente confiaba en que ese hijo suyo fuera una bendición para sí y los demás, que se convirtiera en una ofrenda de gratitud y un canto de adoración al Altísimo.

¿Será que Judá consumó ese noble y elevado ideal para el cual fue consagrado? ¿Cumplió el destino de ser una demostración práctica de alabanza? Si estimamos que Judá preside la lista de los 144000 bienaventurados que personifican los redimidos de acuerdo a Apocalipsis 7: 5-8, hay que concluir que efectivamente logró cumplir con el ideal asignado. No obstante, para llegar a coronar ese fin glorioso tuvo que sortear adversidades y vencer debilidades, errores y actos de cobardía que no fueron una alabanza a Dios, sino por el contrario, imperfecciones de su personalidad. Es que la edificación de un líder 
no se logra por decreto ni es resultado de la generación espontánea, sino un arduo y dificultoso proceso de superación personal, de fracasos y logros.

¿Cómo fue la historia de Judá? Las informaciones bíblicas son escasas, pero las pocas referencias resultan significativas para descubrir los rasgos principales de su personalidad. A continuación consideremos las escenas que retratan a nuestro personaje. Empecemos con Génesis 37, donde se describen los conflictos internos de la familia, que sufría un clima de hostilidad entre los hermanos por las preferencias del padre hacia José, uno de los hermanos más pequeños. Se relata el episodio cuando José es comisionado por su padre para ir al campo donde trabajaban los hermanos. Cuando estos lo vieron llegar con su vestimenta ostentosa que le había regalado el padre, el odio reprimido estalló con violencia fratricida. A pesar de que Rubén quiso salvarlo, ya que siendo el mayor era quien debía tomar las decisiones, fue en realidad Judá quien intervino para sofrenar la furia homicida de sus hermanos. Los persuadió para que no tomaran una medida extrema sino otra más benigna, sugiriendo vender a José como esclavo. El relato da evidencia de su liderazgo cuando declara: "Sus hermanos estuvieron de acuerdo con él" (Gn 37:27, DHH).

Posteriormente los hijos de Jacob urdieron un pérfido complot para engañar al padre y eludir la responsabilidad del mal cometido. Trajeron la ropa ensangrentada de José, teñida con la sangre de un cabrito, sugiriendo al padre que su hijo tan querido podría haber sido despedazado por algún animal feroz (Gn 37:31-35). Durante 22 años sostuvieron esa patraña, viviendo en el fingimiento y la hipocresía. Es probable que Judá no soportó seguir siendo cómplice del engaño, pues abandonó su familia (Gn 38:1). Fue a vivir lejos, vinculándose con gente de dudosa moralidad, que no creía en Dios. Allí estuvo lejos de ser una "alabanza" para convertirse en protagonista de experiencias desventuradas o infaustas.

Se unió a una mujer del pueblo con la cual tuvo tres hijos. Los dos primeros fueron una calamidad. La mala influencia del medio y su incapacidad para educarlos sabiamente fueron la perdición de ellos. El segundo hijo fue un perverso que se hizo tristemente célebre por practicar una aberración sexual que hasta ahora lleva su nombre, "onanismo", pues su nombre era Onán (Gn 38:9-10). Tan escandaloso fue el mal comportamiento de esos hijos que Dios les quitó la vida, muriendo ambos prematuramente. Para peor, las desgracias se acrecentaron para Judá ya que a la pérdida de los hijos, se agregó al poco tiempo el fallecimiento de su esposa, quedando viudo (Gn 38:12).

Pero todavía hubo otro incidente sombrío en esta etapa desdichada de la vida de Judá. Por la ley del levirato reinante en aquella sociedad, le 
correspondía a la nuera, llamada Tamar, casarse con el tercer hijo, ya que al no haber logrado descendencia del marido fallecido tenía el derecho (y quizá el deber) de conseguir descendencia dentro de la familia. En base a esa obligación, Judá le prometió a Tamar entregarle al menor cuando tuviera edad para casarse (Gn 38:11). Pasó el tiempo y no cumplió su promesa. Quizá pensó que sus hijos pudieron haber muerto por culpa de Tamar (negándose a reconocer que fue producto de sus malas vidas), temiendo que el único vivo podría correr igual suerte que sus hermanos. Cuando Tamar descubrió la traición del suegro tramó un plan inaudito. Se disfrazó de prostituta y ofreció sus servicios al mismo Judá, sin que éste la reconociera. Judá cayó en la tentación embarazando a Tamar. Cuando llegó la información de que su nuera estaba encinta, Judá se irritó, acusándola de adúltera. Fue mayúscula su sorpresa cuando descubrió que él era el protagonista del affaire por incumplimiento de su palabra. En esas circunstancias vergonzosas, demostró nobleza de carácter reconociendo su error y haciéndose cargo de los niños que tuvo la nuera que alumbró mellizos.

El Comentario Bíblico Adventista (1CBA, 438), declara al respecto: “Poco podía hacer Judá sino admitir su culpa. Otra vez, como en la trama contra José, reveló un espíritu de honradez y sinceridad por debajo de su conducta a veces escandalosa. Su franca confesión, su trato posterior con Tamar, su éxito en criar a los hijos nacidos de ella, y el hecho de que uno de ellos fue honrado con un lugar en el linaje de Cristo, todo claramente demuestra una completa reforma de su parte. Un carácter más excelente que el de sus hermanos mayores lo hizo idóneo para la dirección de la familia, y habilitó a su posteridad para que ocupara una posición de liderazgo en Israel (caps. 49: 3, 4, 8 10)".

\section{El surgimiento del conductor}

La narración bíblica permite inferir que a partir de esos errores se produjo un cambio medular en el carácter de nuestro héroe, transformándose en un hombre confiable, seguro de sí mismo y con esas cualidades prominentes que distinguen al auténtico líder. Se relatan tres episodios en los cuales se advierten esas cualidades. El primero describe una hambruna entre los pueblos del oriente. Solo Egipto poseía alimentos abundantes. Era inevitable ir a comprarlos a las tierras de los faraones. El gobernador era José ascendido al poder. Por supuesto, sus hermanos no tenían la más mínima sospecha que esa imponente autoridad pudiese ser el mismo joven vendido como esclavo. Los hermanos fueron puestos en un atolladero insuperable a menos que llevaran a Benjamín para demostrar que eran sinceros. Jacob, desde la supuesta muerte 
de José, había convertido a su hijo menor en objeto predilecto de sus afectos y cuidados, viviendo muy apegado a él. No quería pasar nuevamente por la pesadilla de perder a ese único hijo que le quedaba de su amada y difunta Raquel. ¿Cómo convencer al padre que permitiera dejar ir a Benjamín a Egipto para no morir todos por falta de alimentos? El primogénito Rubén intentó persuadir al padre (Gn 42:37), fracasando rotundamente y reforzando en Jacob la negativa. Entonces Judá asumió el desafío. Describe la situación, poniendo un acento emotivo y personal: "Yo me hago responsable, confía en mí". Más que sus argumentos fue su actitud decisiva y confiable, lo que llevó a que Jacob desistiera de su negativa, autorizando el viaje de Benjamín (Gn 42:29-37).

El segundo episodio es el que mejor define las cualidades de líder de Judá. Fue cuando afrontó las circunstancias dramáticas de interceder por la vida de su hermano Benjamín ante el poderoso gobernador de Egipto. José recurrió a una artimaña para acusar a Benjamín de robo y condenarlo a la servidumbre. Aquellos hombres que años atrás habían forzado a la esclavitud al mismo José, ¿ahora qué harían con Benjamín en circunstancias similares? ¿Conservaban la enemistad fraterna o ahora eran capaces de demostrar solidaridad y apego hacia el hermano en desgracia? La oferta fue: "ustedes tienen lo que desean, no se preocupen por su hermano, él será mi esclavo". Pero tantos años sobrellevando la culpa de la ignominia habían sensibilizado sus conciencias y producido un cambio dramático. Quien lideró ese nuevo espíritu de arrepentimiento fue Judá. Con un discurso conmovedor y patético demostró que eran hombres diferentes, dispuestos a sacrificar sus vidas por un hermano (Gn 44:18-34). Ese momento trasluce con prodigiosa intensidad la nobleza de carácter, la abnegación y la actitud de renunciamiento de Judá. Tan emocionante fueron sus palabras que José no tuvo dudas de la probidad de sus hermanos y no pudo más seguir finjiendo, dándose a conocer en una de las escenas más enternecedoras de la Biblia, cuando todos los hermanos lloraron abrazados de alegría por el reencuentro y la reconciliación.

El tercer ejemplo de liderazgo de Judá se aprecia cuando Jacob y su familia se trasladan a Egipto. El patriarca decide enviar un emisario delante de la comitiva, como su representante personal (Gn 46:28), encargado de resolver las dificultades que pudieran surgir en el camino. La persona escogida fue precisamente Judá.

En resumen, Judá se distinguió por la lógica persuasiva de sus argumentos y la capacidad para influir sobre la gente. Tenía un carisma especial para ser reconocido y aceptado como líder. Poseía la rara virtud de actuar sobre los ánimos y las voluntades con fuerza sugestiva. No se amedrentó ante las 
dificultades, por el contrario, reunió aptitudes y habilidades especiales para enfrentar los más difíciles problemas con éxito. Por eso, el padre, en su lecho de muerte (ver epígrafe) lo comparó a un "cachorro de león" y con vocación profética anticipó que de su descendencia vendría "el dueño del cetro, a quien los pueblos obedecerán".

\section{Descendencia privilegiada}

La biografía de Judá es la puesta en escena de la dimensión ética del liderazgo, de la construcción del conductor, de una suerte de arquitectura del héroe bíblico. Se adueñó del estrellato de la primogenitura (según Gn 49:8-12 y Ap 7: 5-8), no en forma extorsiva ni conspirativa, sino gracias al reconocimiento de sus congéneres y la entrega generosa de su vida altruista. Tampoco abusó de la exaltación verbal ni del histrionismo, sino de la persuasión a través de la lógica de la razón. Sus nobles cualidades de carácter las trasmitió a sus descendientes, constituyendo una genealogía prodigiosa de líderes destacados que hicieron historia cuando les tocó vivir. De él nació el heroico conquistador Caleb (Jos 14:6; 2 Cr 2:18), el misericordioso Obed (Rt 4:18-21), el juez libertador Otoniel (Jue 3:9), el impecable profeta Daniel (Dn 1:3) y sus tres valientes compañeros, además de una multitud de reyes, empezando por el dulce cantor de Israel, el rey David, seguramente el más encumbrado personaje de la tribu de Judá, con excepción del Mesías, el Rey de reyes y Señor de Señores, Jesucristo.

La historia bíblica rememora la escena patética del final de la vida del patriarca Jacob o Israel. Estando en su lecho de muerte, ante la eminencia de la muerte, convoca a todos sus hijos para la despedida. Entonces, en una especie de arrebato clarividente, dirige a cada hijo un mensaje postrero con proyecciones proféticas abriendo las puertas del futuro de sus sucesores y sus respectivos linajes. "Dio a Judá las bendiciones que correspondían al primogénito (Gn 49:8-12), pasando por alto a Rubén por su pecado de incesto (v.4), y a Simeón y Leví por su matanza de los siquemitas (vs. 5-7)" (DBA, "Jacob"). Con voz sonora y profunda el patriarca anticipó siglos y milenios, cuando sentenció sobre ese hijo distinguido: “No será quitado el cetro de Judá, y el legislador de entre sus pies, hasta que venga Siloh; y a él se congregarán los pueblos" (Gn 49:10). Las palabras del patriarca quedaron resonando en el recinto ante la admiración y el asombro de todos, trascendiendo las paredes y los tiempos para ser una de los primeros anuncios del nacimiento de Jesús y aun traspasar nuestros propios días apuntando a la segunda venida de Cristo 
cuando finalmente "se congregarán los pueblos".

¿Por qué Judá fue comparado con un cachorro de león? Porque su persona, acrisolada en las luchas de la vida, anunciaba la madurez de su estirpe, ya que de él surgiría el hijo de David, Siloh, el verdadero "León de la tribu de Judá" (Ap 5:5 6), Jesucristo el Mesías. Ese descendiente privilegiado sería el centro de todas las "alabanzas", ante quien todos los poderes de la tierra se inclinarán y todas las naciones le rendirán homenaje en aquel día final de la historia del mundo. Los aspectos más destacados del carácter de Judá fueron figura de lo porvenir. Su sentido de vida orientado a la alabanza y especialmente a la entrega y la disposición al sacrificio que manifestara Judá reprodujo en forma anticipada el martirio vicario de Jesucristo, su glorioso descendiente eterno. La tribu de Judá llegó a ser la más importante de todas las de Israel, la única que pudo conservar su identidad con el paso de los siglos y milenios. Aún el resto de los israelitas son conocidos como "judíos". Ojalá que todos los que lleven ese distinguido nombre puedan reproducir el carácter privilegiado de su prócer originador, asumiendo la función de un liderazgo de poder y alabanza.

Mario Pereyra Lavandina Universidad de Montemorelos email: pereyram@um.edu.mx

Recibido: 02 de agosto de 2012 Aceptado: 25 de Setiembre de 2012 
Mario Pereyra Lavandina

\section{Referencias}

Horn, S.H. (1987). Diccionario Bíblico Adventista. Asociación Casa Editora Sudamericana, Florida, Buenos Aires (abreviado como DBA).

Lipovetsky, G. y Charles, S. (2006). Los nuevos tiempos hipermodernos. Anagrama, Barcelona

Nichol, F. (1995). Comentario Bíblico Adventista del Séptimo Día. Asociación Casa Editora Sudamericana, Florida, Buenos Aires (abreviado como CBA, con el número del toma adelante).

Rojas, E. (1999). El hombre light. Una vida sin valores. Planeta, Buenos Aires.

Vargas Llosa, M. (2012). La civilización del espectáculo. Alfaguara, México 